\title{
Development of Model Solar Kitchen with Green Energy for Demonstration and Application in Rural Areas
}

\author{
Sanjib Kumar Rout \\ C.V. Raman College of Engineering, Bidyanagar, Mahura, Janla, Bhubaneswar-752054, India \\ *Telephone: 91-674 2460043/2460093, FAX-91-674246009, Email-sanjibrout.1@gmail.com
}

\begin{abstract}
The paper demonstrates how effectively hoteliers and corporate can architect and utilize both solar thermal and green gas energy for the production of zero carbon foot print food products. It involves the usage of shefflers, solar parabolic reflectors, solar ovens, solar cookers, solar dryers, solar water heaters, biomass gasifiers, biogas plant, etc which have been suitably designed and placed architecturally in the green kitchen premises to harvest maximum solar thermal green energy for effective production of low and zero carbon foot print food products with minimal loss of nutritional value. Further, the digested slurry of biogas plant is used as humus rich fertilizer for spice garden spread around the green kitchen to beautify the ambient. Replacement of conventional energy partially by green and thermal energy reduces the energy cost substantially. It not only cuts down the cost of fuel but also maintains a clean environment in canteen area and its surroundings in addition to providing nutritious food. The methods developed in this project may also be implemented in vast rural mass and community centre for cost effective and hygienic food production.
\end{abstract}

Keywords: Fossil fuel, Carbon foot print, Green canteen, Solar energy, Biomass energy

\section{Introduction:}

Today, India is growing with an average GDP growth of 8.9\% per annum, which signifies the tremendous growth of its economy. Massive investment are being laid out by the Government and private sectors for the development of small and large manufacturing software industries and in service sectors like education, healthcare, hotels and real estates. These are being constructed throughout the country and environment becomes a concern everywhere. Our Government is enforcing norms to ensure that all these projects remain as much greener as possible. In any corporate offices, hotels, schools and colleges, quantity kitchen is mandatory to support their employees, students and customers so that they can avail nutritional food [1]. A survey has been conducted with some hotels and schools located in the rural part of Odisha State of our Country about the greenery of their kitchen and about their waste disposal. Today most of these industries, corporate offices, hotels and motels are very much aware of the energy saving equipment but have least ideas to make their environment green by applying the cheapest and easiest methods of non-conventional energy [2]. We tried to collect the feedback to understand their knowledge about energy saving devices, carbon emission, carbon footprint products and application of non-conventional energy for quantity kitchen.

It is a matter of concern of rural hotels and schools where food is prepared for more than 500 people per day with all conventional fuel and equipment. Our survey found most of these organizations trying to project their awareness by using energy efficient electrical and ceramic appliances, low-cost wood and coal steamers and also by disposing the food waste in isolated places without making the assessment how much damage is made to the environment [3].

The aim of this project is to develop a model green kitchen to demonstrate an effective and cheaper prototype which shall 
1. Reduce carbon dioxide emission to a substantial level by the application of solar thermal reflectors, ovens and driers [4].

2. Establish a convenient waste management system and through it produce methane in order to utilize it in the kitchen [5] and to generate bio-fertilizer for its easy utilization in the spice garden.

3. Produce zero carbon footprint food products with higher nutritional value.

4. Reduce the total operational cost by at least $40 \%$ of the conventional one.

\section{Materials and Methodology}

\subsection{Materials for green kitchen and its layout}

A green kitchen attached to a 500 person capacity quantity kitchen was established at C.V. Raman College of Engineering, Bhubaneswar, India as per the layout shown in Fig. 1.

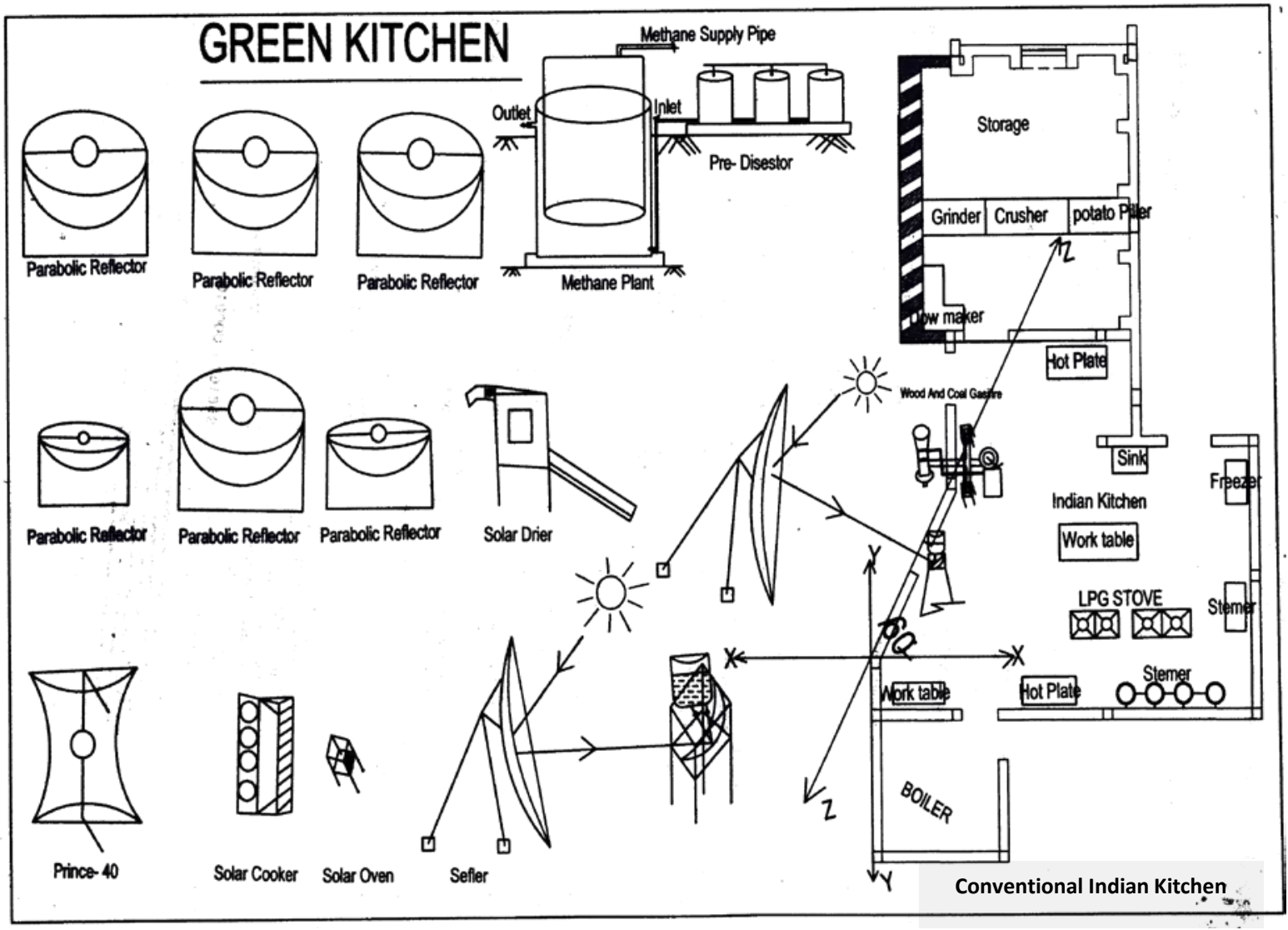

Fig. 1 Layout of green kitchen

Devices like solar reflectors of parabolic type, Schefflers, solar dyers, solar oven [6], solar water heaters, biomass gasifier and a food waste digester methane plant were installed. All these equipments have been installed by taking the following points into consideration:

1. The conventional kitchen wall facing the Scheffler was in east-west direction

2. Sheffler foundation was done taking latitudinal angle into consideration[7]

3. Thermal reflectors were located where maximum sun-light is available [8]

4. Schefflers fixed focus concentrator

5. Methane plant was installed near the conventional kitchen wall with less sun-light 
From the survey conducted, it was realized that the small, medium and large hotels and motels of the locality had expressed serious concern regarding the effective utilization of solar thermal equipments in quantity food preparation and found that the food waste disposal outside the kitchen boundary as the most easiest and cheapest way. By way of this disposal, they were ignorant about the emission of methane gas to the atmosphere which has more than 20 time green house effect than that of carbon dioxide gas. They were also very much doubtful to accept the concept of the reduction fuel consumption by the food waste.

The layout of solar and green energy devices as shown Fig. 1 was designed for the demonstration to hoteliers and corporate to observe as well as analysed how the green kitchen effective and convenient for the reduction of cost of food production. This project had taken all the observations and experiments considering 78,000 Lux intensity of sun light as a reference during the month of August to December, the winter season. In a sunny day of the period green kitchen was able to cook grains, vegetables, meats and produce hot water continuously for more than six hours in a day from 9 hour morning to 15 hour evening. During summer the Lux intensity of sun light might rise for the locality as per temperature weather relationship curve, shown in Fig. 2 [7].

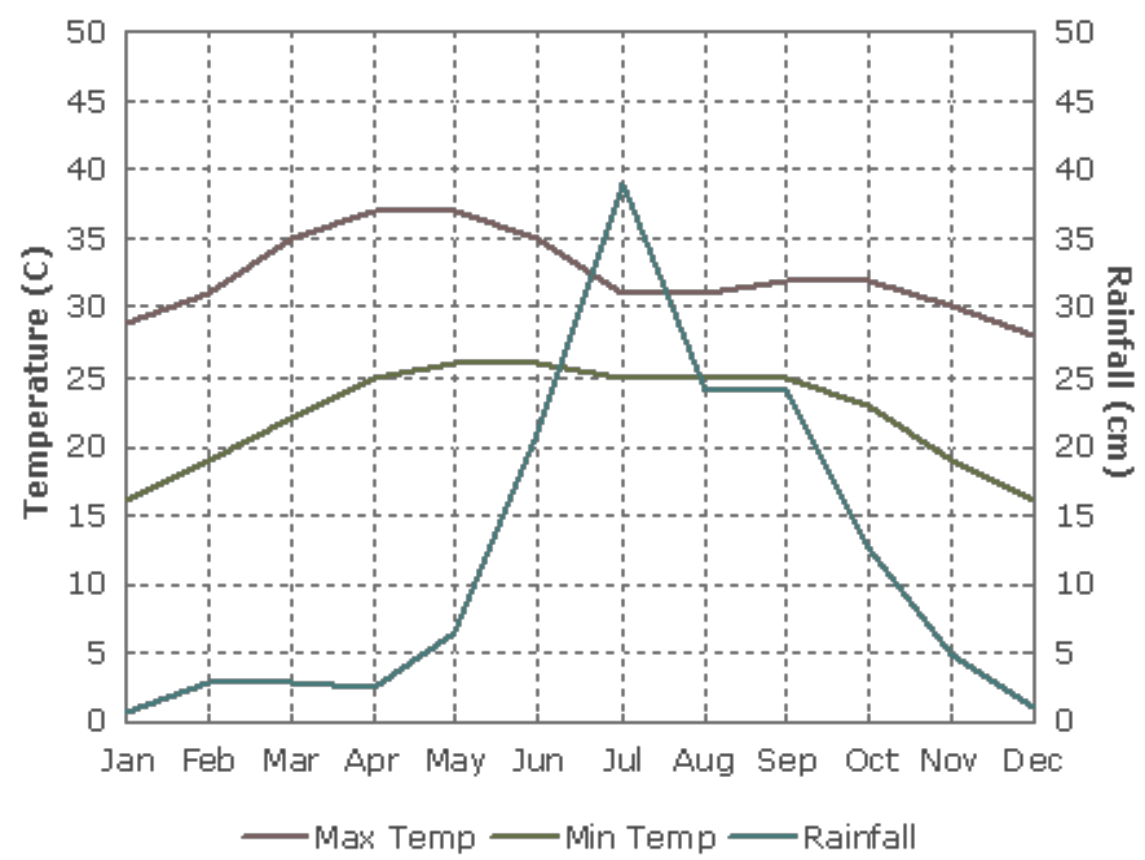

Fig. 2 Relationship of atmospheric temperature, average rain fall vs season

\subsection{Methods adopted for the installation of green energy devices}

The details of green energy devices are presented in Fig. 3 along with specification and cost. 


\begin{tabular}{|c|c|c|c|}
\hline Sl. No. & Name of equipment & Photograph & $\begin{array}{l}\text { Cost of the equipment (in } \\
\text { Indian Rupees) }\end{array}$ \\
\hline 01 & Scheffler - 1 & & 80,000 \\
\hline 02 & Scheffler - 2 & & $1,20,000$ \\
\hline 03 & Parabolic reflector-1 & & 37,000 \\
\hline 04 & Parabolic reflector-2 & & 32,000 \\
\hline 05 & Solar drier & & 10,000 \\
\hline 06 & Solar oven & & 3,000 \\
\hline 07 & Solar water heater & & $1,00,000$ \\
\hline 08 & Methane plant & & $5,00,000$ \\
\hline 09 & Biomass gassifier & & 10,000 \\
\hline & & & $8,92,000$ \\
\hline
\end{tabular}

Fig. 3 The detailed specification and cost of green energy devices 


\subsection{Theoretical background for the installation of Scheffler}

The installation of Scheffler- 1 disc above the ground was taken as $5.2 \mathrm{~m}$ and the distance of the receiver from the disc centre as $3.8 \mathrm{~m}$ while the height of the receiver above the ground was evaluated using the equation 1.

$$
\mathrm{Y}=\mathrm{B}-\left\{\mathrm{X}^{*} \sin (\mathrm{A})\right\}
$$

where, $\mathrm{Y}=$ height of the receiver, $\mathrm{B}=$ height of the disc above the ground, $\mathrm{X}=$ distance of receiver from disc centre and, $\mathrm{A}=$ latitudinal angle at any place

In order to keep the focal line constant, orientation of scheffler was adjusted with a programmable motor fitted device as per the movement of the solar rays on earth.

\subsection{Basic principles of the installation of other solar devices}

\subsubsection{Parabolic Reflector}

Both parabolic reflectors shown in Fig. 3 (Sl. No. 1 \& 2 - Schefflers) and (Sl. No. 3 \& 4 Prince-40) [9] were installed to receive full sun rays and get concentrated on fixed focal centre through reflection where the cooker was placed with blacken surface to absorb maximum thermal energy. Here also the orientation of reflectors were adjusted with a programmable motor fitted device as per the movement sun rays

\subsubsection{Solar dryer}

The solar dryer was designed on the principle of green house glass where high frequency solar radiation got absorbed through inclined glass surface by the food materials but longer wavelength radiations reflected out. Moisture content was continuously ventilated. The inclination angle was experimentally evaluated to receive maximum temperature.

\subsection{Methane Plant}

The cellulosic materials comprising both vegetable waste and food waste of the canteen are predigested aerobically. The digested slurry with high biological oxygen was an aerobically digested to methane rich biogas which was purified by the separation of carbon dioxide gas. The high calorific methane rich gas was found to produce $0.6 \times 10^{-3} \mathrm{~m}^{3}$ of methane gas per $\mathrm{kg}$ of cellulosic waste on dry basis. The digested effluent was found to be rich in $\mathrm{P}_{2} \mathrm{O}_{5}$ with small quantity of $\mathrm{K}_{2} \mathrm{O}$ and Nitrogen ingredients to act as ideal fertilizer for spice garden making the hotel environment greener, beautiful and profitable.

\subsection{Biomass gasifier}

Waste dry biomass collected by locals was fired in the special designed oven and thermal energy was fire through exhaust fan drive in a special designed energy efficient oven to utilize its maximum thermal energy by the cooking vessel.

\section{Results and Discussion}

\subsection{Cost analysis of equipments}

The cost of all equipments utilized in the project with respect to the cost in Indian market are worked out and compared with the conventional devices adopted by hoteliers, etc. on the basis of preparing food for 500 consumers as given in Table 1. 
Table 1: Equipments used in a conventional kitchen to prepare food for 500 persons

\begin{tabular}{cl}
\hline Sl. No. & Name of the equipment \\
01 & Cooking Range 4 Burner (LPG) \\
02 & Cooking range High Pressure \\
03 & Convection oven \\
04 & Griddle \\
05 & Stock Pot Burner \\
06 & Deep fat fryer (2 Comp.) 5 Ltr. \\
07 & Potato Peeler Heavy Duty \\
08 & Dough mixer \\
09 & Steamer compartment with boiler \\
10 & Tandoor (Gas/coal) \\
11 & Thawing tub \\
12 & Vegetable slicer \\
13 & Chapatti Puffer cum holplate \\
14 & Aluminium steamer idli \\
15 & Deep freezer \\
16 & Vegetable steamer big \\
17 & Hot dog roller \\
\hline
\end{tabular}

The conventional Indian quantity kitchen cost is around Rs. 25 Lakhs. This is three times the cost of the green kitchen. Making a simple comparison of the total cost of a green kitchen and a quantity kitchen we have found that the former is $30 \%$ less.

\subsection{Cost saving analysis}

In this exercise, we have tried to calculate the savings of fossil fuel per day by utilizing all these green equipments for preparing the following items:

a. Preparation of rice, b. Preparation of vegetables, c. Preparation of meat, d. Preparation of grains. In this total exercise (Table 2), it is calculated in a sunny day by utilizing this green kitchen. Fig. 2 shows the atmospheric temperature and rain fall profile in a year at the surveyed place.

Table 2: Saving of fossil fuel, its cost and environmental benefits by the implementation of solar thermal devices and methane gas plant for 500 people per meal

\begin{tabular}{|c|c|c|c|c|c|c|c|c|}
\hline \multirow{2}{*}{$\begin{array}{l}\text { Sl. } \\
\text { no. }\end{array}$} & \multirow[t]{2}{*}{ Recipe } & \multicolumn{2}{|l|}{ Quantity } & \multirow{2}{*}{$\begin{array}{l}\text { Ambience } \\
\text { of light } \\
\text { (Lux) }\end{array}$} & \multirow{2}{*}{$\begin{array}{l}\text { Total time } \\
\text { taken } \\
\text { (Min.) }\end{array}$} & \multicolumn{3}{|c|}{ Quantity of savings of } \\
\hline & & Ingredient & $\begin{array}{l}\text { Water } \\
\text { (Lit.) }\end{array}$ & & & $\begin{array}{l}\text { Fossil } \\
\text { fuel(kg) }\end{array}$ & $\begin{array}{l}\mathrm{CO} \\
2 \\
(\mathrm{~kg}) \\
\end{array}$ & $\begin{array}{l}\text { Cost } \\
\text { (Rs.) }\end{array}$ \\
\hline 01 & $\begin{array}{l}\text { Cooked } \\
\text { rice }\end{array}$ & $\begin{array}{l}\text { Raw rice } \\
(60 \mathrm{~kg})\end{array}$ & 144 & 78,000 & 72 & 9.6 & 29 & 288 \\
\hline 02 & Vegetables & $\begin{array}{l}\text { Vegetables } \\
(75 \mathrm{~kg})\end{array}$ & 60 & 78,000 & 69 & 12 & 36 & 360 \\
\hline 03 & Grains & Dal (25 kg) & 90 & 78,000 & 108 & 6.75 & 18 & 180 \\
\hline 04 & Meat & $\begin{array}{l}\text { Chicken } \\
\text { (70 kg) }\end{array}$ & 252 & 78,000 & 108 & 16.8 & 50 & 504 \\
\hline
\end{tabular}


To prepare two meals in a day for 500 people the employed boiler consumes about $40 \mathrm{~kg}$ fire woods. On the other hand, upon employing gasifier it reduces $50 \%$ of fire wood $(20 \mathrm{~kg})$ consumption in addition to $20 \mathrm{~kg}$ equivalent of $\mathrm{CO}_{2}$ emission.

Approximately $120 \mathrm{~kg}$ of food waste is produced daily from the canteen emitting $\mathrm{CH}_{4}$ and $\mathrm{CO}_{2}$ as green house gases to the environment. Methane $\left(\mathrm{CH}_{4}\right)$ has 21 times stronger green house effect than $\mathrm{CO}_{2}$. By generating bio gas out of this food wastes and considering all losses into account about 4 lakhs Indian rupees is saved in compensation to LPG consumption.

\subsection{Application in spice garden}

In most of the hotels, motels and corporate we have seen they spent a substantial amount of money in manure to keep their garden attractive and flowering. In our project we have introduced a concept of organic spice garden which we have demonstrated by doing a beautiful green landscape and planting 63 varieties of spices in the garden as an alternative to traditional rock and flower garden. In this food waste plant which we have installed that contains digested effluent which is being utilized in this spice garden to grow healthy and produce organic spices which can be reutilize in kitchen by using all the food wastes in the system.

We are yet to calculate the total value of spices generated in 1.5 acres of land in one year which can be worked out in the next year.

\subsection{Theoretical background for architect}

Green kitchen can be installed very conveniently at low installation cost if it is planned during the construction of the project. Architect should have fundamental knowledge about the geographical location of the place for installation of thermal reflectors because they can adjust the floor level of the kitchen to an operational height which cannot be done with an established kitchen. We have given an example of 4 places and shown a calculation as per equation (1) conveying the idea of geographical location of the place is important to install the thermal reflectros as shown in Fig. 4.
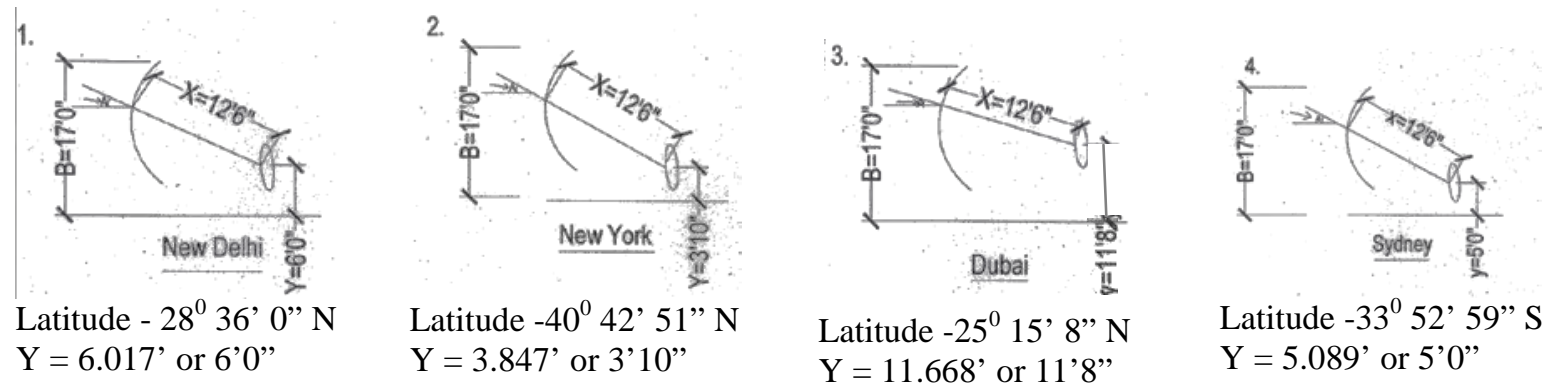

Fig. 4: Diagram showing the angle of incidence of solar ray on Scheffler and its height from the ground at different location

This study shows if the architect is aware of these factors then will keep in mind so that the reflector can be installed at a convenient height for operation. Apart from reflector the architecture should workout for disposal of waste from methane plant in such a way that it will not have any negative impact on the environment and kitchen surroundings, so that the waste can be easily pumped to the green kitchen site. 


\section{Conclusion}

The C.V. Raman College of Engineering, Bhubaneswar, India has successfully installed a composite 500 students green kitchen project for demonstration to hoteliers, corporate that how effectively to produce low and zero carbon foot print food products and also to incorporate this concept during design stage. On total in a year (operation of 6 months) using this green kitchen, around 4.8 lakh Indian rupees is saved than the conventional method of cooking along with a reduction of about $48,000 \mathrm{~kg}$ of green house gas emission to the environment. $50 \%$ utilization of green kitchen in an annum, it has been evaluated that the total investment is fully recovered in a year in addition to providing tremendous safety to the environment. The methods developed in this project may also be demonstrated to vast rural mass and community centre for cost effective and hygienic food production.

\section{References}

[1] Blaine P. Friedlander Jr. Sweden, Researchers at school of Medicine, New York, Dr Vlassara, National Academy of Sciences, Proceedings from World Conference of Advances in Solar Cooking \& The Times of India (14 ${ }^{\text {th }}$ Nov. 2002)

[2] Suhatme S.P., Solar energy principles of thermal collection and storage, New Delhi: Tata McGraw-Hill; 1996

[3] Parkin G.F., Own W.F., Fundamentals of anaerobic digestion of waste water sludge, J. Environ. Eng.-ASCE 112, 1986, pp. 867-920

[4] Alexopoulos, S., Hoffschmidt, B Solar tower power plant in Germany and future perspectives of the development of the technology in Greece and Cyprus, Renewable Energy 35, 2010, pp. 1352-1356

[5] Standard methods for the examination of water and wastewater. 19th ed. Washington, DC: APHA-AWWA-WEF; 1995

[6] Mullick S.C., Kandpal T.C. and Subhod Kumar, Thermal test procedure for paraboloid concentrator solar cooker, Solar Energy 46, 1991, pp. 139-144

[7] Chung T.M., A study of luminous efficacy of daylight in Hong Kong, Energy Buildings 19, 1992, 45

[8] Temps R.C., Coulson KL. Solar radiation incident upon slopes of different orientations, Sol Energy 19, 1977, pp. 179-84

[9] Ajay Chandak: Paraboloidal Solar Concentrator with Square / Rectangular Sections: Patent Application no. 581/MUM/2008 with Indian Patent Office. 